\title{
Definition, Diagnosis, Treatment, and Prognosis of Frozen Shoulder: A Consensus Survey of Shoulder Specialists
}

\author{
Chul-Hyun Cho, MD, Yong-Ho Lee, MD, Du-Hwan Kim, MD*, Young-Jae Lim, MD ${ }^{\dagger}$, \\ Chung-Sin Baek, MD, Du-Han Kim, MD \\ Departments of Orthopedic Surgery and * Rehabilitation Medicine, Dongsan Medical Center, Keimyung University School of Medicine, Daegu, \\ ${ }^{\dagger}$ Department of Orthopedic Surgery, The Open Hospital, Daegu, Korea
}

\begin{abstract}
Background: The objective of this study was to identify a consensus on definition, diagnosis, treatment, and prognosis of frozen shoulder (FS) among shoulder specialists.

Methods: A questionnaire composed of 18 questions about FS — definition, classification, utilization of diagnostic modalities, the propriety of treatment at each stage, and prognosis - was sent to 95 shoulder specialists in Korea. Most questions (15 questions) required an answer on a 5-point analog scale (1, strongly disagree; 5, strongly agree); three questions about the propriety of treatment were binary.

Results: We received 71 responses (74.7\%). Of the 71 respondents, 84.5\% agreed with the proposed definition of FS, and 88.8\% agreed that FS should be divided into primary and secondary types according to the proposed definition. Only $43.7 \%$ of the respondents agreed that FS in patients with systemic disease should be classified as secondary FS. For the diagnosis of FS, 71.9\% agreed that plain radiography should be used and $64.8 \%$ agreed ultrasonography should be used. There was a high consensus on proper treatment of FS: $97.2 \%$ agreed on education, $94.4 \%$, on the use of nonsteroidal anti-inflammatory drugs; $76.1 \%$, on intra-articular steroid injections; and $97.2 \%$, on stretching exercise. Among all respondents, $22.5 \%$ answered that more than $10 \%$ of the patients with FS do not respond to conservative treatment.

Conclusions: The survey revealed a general consensus among shoulder specialists on the definition and treatment of FS. However, classification of FS was found controversial.

Keywords: Frozen shoulder, Definition, Classification, Diagnosis, Treatment
\end{abstract}

Frozen shoulder (FS), also known as adhesive capsulitis, is a common pathologic condition of the shoulder joint. It is characterized by progressive shoulder pain and restriction of the range of motion. ${ }^{1)}$ Despite its prevalence, FS is one of the most poorly understood shoulder conditions. Its definition, classification, pathophysiology, diagnosis, natu-

Received January 9, 2019; Accepted March 26, 2019

Correspondence to: Du-Han Kim, MD

Department of Orthopedic Surgery, Dongsan Medical Center, Keimyung University School of Medicine, 56 Dalseong-ro, Jung-gu, Daegu 41931, Korea Tel: +82-53-250-8160, Fax: +82-53-250-7205

E-mail: osmdkdh@gmail.com ral course, treatment, and prognosis remain controversial. $^{2-5)}$ Zuckerman and Rokito ${ }^{6)}$ surveyed members of the American Shoulder and Elbow Surgeons (ASES) association on the definition of FS to assist clinicians in counseling patients with FS. They reported that the heterogeneity of the definition and classification of FS in previous studies makes it difficult to compare the outcome and prognosis of different studies that describe either diagnostic or treatment modalities. ${ }^{\text {) }}$

In 1934, Codman ${ }^{7)}$ suggested that FS will resolve spontaneously even in most severe cases regardless of treatment. However, clinicians often encounter patients complaining of residual pain and loss of motion even at 2 
Cho et al. A Consensus Survey of Shoulder Specialists on Frozen Shoulder

Clinics in Orthopedic Surgery • Vol. 12, No. 1, $2020 \bullet$ www.ecios.org

years after the onset of the disease. ${ }^{8,9)}$ Common nonoperative strategies used to treat FS include supervised neglect, use of nonsteroidal anti-inflammatory drugs (NSAIDs) or oral corticosteroids, corticosteroid injection, physical therapy, hydrodilatation, and manipulation under anesthesia (MUA). ${ }^{10-17)}$ Although medical experts in various fields

Table 1. Questions and Answers about Frozen Shoulder

Definition of frozen shoulder

01. Frozen shoulder is a self-limiting disease characterized by pain and functional restriction in both active and passive shoulder motion lasting more than 1 month, for which radiographic findings of the shoulder joint are unremarkable.

02. Frozen shoulder is categorized as either primary or secondary. Primary frozen shoulder is considered a diagnosis for all cases in which specific trauma, known comorbidity, or underlying etiology cannot be identified. Secondary frozen shoulder is considered when known associated conditions are identified.

03. Limitation of motion in stage II (frozen phase) or III (thawing phase) is defined as limitation of more than $30^{\circ}$ in more than two directions (forward flexion, abduction, external rotation, or internal rotation)

\section{(1) Strongly disagree}

(2) Disagree

(3) No opinion

(4) Agree

(5) Strongly agree

(1) Strongly disagree

(2) Disagree

(3) No opinion

(4) Agree

(5) Strongly agree

(1) Strongly disagree

(2) Disagree

(3) No opinion

(4) Agree

(5) Strongly agree

Q4. Do you think that frozen shoulder diagnosed in patients with systemic disease such as thyroid disease or hyperlipidemia should be considered secondary?

(1) Strongly disagree

(2) Disagree

(3) No opinion

(4) Agree

(5) Strongly agree
05. Do you think that frozen shoulder diagnosed in patients with diabetes should be considered secondary?

(1) Strongly disagree

(2) Disagree

(3) No opinion

(4) Agree

(5) Strongly agree

Q6. Do you think that frozen shoulder after minor trauma or overuse should be regarded as primary?

(1) Strongly disagree

\begin{tabular}{|c|c|c|c|c|}
\hline (1) Strongly disagree & $4(5.6)$ & $4(5.6)$ & 26.7 & 67.6 \\
\hline (2) Disagree & $15(21.1)$ & $19(26.7)$ & & \\
\hline (3) No opinion & $4(5.7)$ & $23(32.4)$ & & \\
\hline (4) Agree & $39(54.9)$ & $62(87.3)$ & & \\
\hline (5) Strongly agree & $9(12.7)$ & $71(100)$ & & \\
\hline
\end{tabular}

\begin{tabular}{|c|c|c|c|}
\hline \multicolumn{2}{|c|}{$N=71$} & & Aqree \\
\hline Number $(\%)$ & $\begin{array}{l}\text { Cumulative } \\
\text { number }(\%)\end{array}$ & $\begin{array}{c}\text { opinion } \\
\text { percent (1) or (2) }\end{array}$ & $\begin{array}{c}\text { opinion } \\
\text { percent (4) or (5) }\end{array}$ \\
\hline
\end{tabular}

\begin{tabular}{|c|c|c|c|}
\hline $3(4.2)$ & $3(4.2)$ & 15.5 & 84.5 \\
\hline $8(11.3)$ & $11(15.5)$ & & \\
\hline 0 & $11(15.5)$ & & \\
\hline $41(57.7)$ & $52(73.2)$ & & \\
\hline $19(26.8)$ & $71(100)$ & & \\
\hline
\end{tabular}

$1(1.4)$

$1(1.4)$

8.4

88.8

$5(7)$

6 (8.4)

2 (2.8)

$8(11.2)$

26 (36.6)

34 (47.8)

$37(52.2)$

71 (100)

$4(5.6)$

$4(5.6)$

22.5

69.0

12 (16.9)

16 (22.5)

6 (8.5)

22 (31)

43 (60.6)

65 (91.6)

$6(8.4)$

71 (100)

12 (16.9)

12 (16.9)

36.6

43.7

14 (19.7)

26 (36.6)

14 (19.7)

40 (56.3)

19 (26.8)

59 (83.1)

12 (16.9)

71 (100)

11 (15.5)

11 (15.5)

40.9

45.0

18 (25.4)

29 (40.9)

10 (14.1)

39 (55.0)

17 (23.9)

56 (78.9)

15 (21.1)

$71(100)$

4 (5.6)

26.7

67.6 


\section{Table 1. Continued 1}

\begin{tabular}{|c|c|c|c|c|c|}
\hline \multirow{2}{*}{ Definition of frozen shoulder } & & \multicolumn{2}{|c|}{$\mathrm{N}=71$} & \multirow{2}{*}{$\begin{array}{l}\text { Disagree } \\
\text { opinion percent } \\
\text { (1) or (2) }\end{array}$} & \multirow{2}{*}{$\begin{array}{l}\text { Agree } \\
\text { opinion } \\
\text { percent (4) or } 5\end{array}$} \\
\hline & & Number (\%) & $\begin{array}{l}\text { Cumulative } \\
\text { number }(\%)\end{array}$ & & \\
\hline \multirow{5}{*}{$\begin{array}{l}\text { Q7. Do you use plain radiography in diagnosis } \\
\text { of frozen shoulder? }\end{array}$} & (1) Strongly disagree & $5(7)$ & $5(7)$ & \multirow[t]{5}{*}{28.1} & \multirow[t]{5}{*}{71.9} \\
\hline & (2) Disagree & $15(21.1)$ & $20(28.1)$ & & \\
\hline & (3) No opinion & 0 & $20(28.1)$ & & \\
\hline & (4) Agree & $32(45.1)$ & $52(73.2)$ & & \\
\hline & (5) Strongly agree & $19(26.8)$ & $71(100)$ & & \\
\hline \multirow{5}{*}{$\begin{array}{l}\text { 08. Do you use ultrasonography in diagnosis } \\
\text { of frozen shoulder? }\end{array}$} & (1) Strongly disagree & $4(5.6)$ & $4(5.6)$ & \multirow[t]{5}{*}{31.0} & \multirow[t]{5}{*}{64.8} \\
\hline & (2) Disagree & $18(25.4)$ & $22(31)$ & & \\
\hline & (3) No opinion & $3(4.2)$ & $25(35.2)$ & & \\
\hline & (4) Agree & $28(39.4)$ & $53(74.6)$ & & \\
\hline & (5) Strongly agree & $18(25.4)$ & $71(100)$ & & \\
\hline \multirow{5}{*}{$\begin{array}{l}\text { 09. Do you use magnetic resonance } \\
\text { imaging in diagnosis of frozen shoulder? }\end{array}$} & (1) Strongly disagree & $7(9.9)$ & $7(9.9)$ & \multirow[t]{5}{*}{57.8} & \multirow[t]{5}{*}{36.5} \\
\hline & (2) Disagree & $34(47.9)$ & $41(57.8)$ & & \\
\hline & (3) No opinion & $4(5.7)$ & $45(63.5)$ & & \\
\hline & (4) Agree & $18(25.3)$ & $63(88.8)$ & & \\
\hline & (5) Strongly agree & $8(11.2)$ & $71(100)$ & & \\
\hline \multirow{5}{*}{$\begin{array}{l}\text { 010. Factors such as the types or dose of local } \\
\text { anesthesia or volume of normal saline, not the } \\
\text { dose of corticosteroid, affect the outcome. }\end{array}$} & (1) Strongly disagree & $3(4.2)$ & $3(4.2)$ & \multirow[t]{5}{*}{33.8} & \multirow[t]{5}{*}{47.9} \\
\hline & (2) Disagree & $21(29.6)$ & $24(33.8)$ & & \\
\hline & (3) No opinion & $13(18.3)$ & $37(52.1)$ & & \\
\hline & (4) Agree & $24(33.8)$ & $61(85.9)$ & & \\
\hline & (5) Strongly agree & $10(14.1)$ & $71(100)$ & & \\
\hline \multirow{5}{*}{$\begin{array}{l}\text { 011. An image-guided technique is necessary } \\
\text { for intra-articular corticosteroid injection. }\end{array}$} & (1) Strongly disagree & $4(5.6)$ & $4(5.6)$ & \multirow[t]{5}{*}{25.3} & \multirow[t]{5}{*}{70.5} \\
\hline & (2) Disagree & $14(19.7)$ & $18(25.3)$ & & \\
\hline & (3) No opinion & $3(4.2)$ & $21(29.5)$ & & \\
\hline & (4) Agree & $31(43.7)$ & $52(73.2)$ & & \\
\hline & (5) Strongly agree & $19(26.8)$ & $71(100)$ & & \\
\hline \multirow{5}{*}{$\begin{array}{l}\text { Q12. How many times do you perform intra-articular } \\
\text { corticosteroid injection in a single patient? }\end{array}$} & (1) Not necessary & $7(9.9)$ & $7(9.9)$ & & \\
\hline & (2) Once & $44(62.0)$ & $51(71.9)$ & & \\
\hline & (3) Twice & $14(19.7)$ & $65(91.6)$ & & \\
\hline & (4) Three times & $5(7.0)$ & $70(98.6)$ & & \\
\hline & (5) Four times or more & $1(1.4)$ & $71(100)$ & & \\
\hline
\end{tabular}


Cho et al. A Consensus Survey of Shoulder Specialists on Frozen Shoulder

Clinics in Orthopedic Surgery • Vol. 12, No. 1, $2020 \bullet$ www.ecios.org

\section{Table 1. Continued 2}

\begin{tabular}{|c|c|c|c|c|c|}
\hline & & & & & \\
\hline Definition of frozen shoulder & & Number (0) & Cumulative & opinion percent & $\begin{array}{l}\text { opinion } \\
\text { nercent } 4 \text { or } 5\end{array}$ \\
\hline 013. Intra-articular corticosteroid injection & (1) Strongly disagree & $1(1.4)$ & $1(1.4)$ & 23.9 & 63.4 \\
\hline & (2) Disagree & $16(22.5)$ & $17(23.9)$ & & \\
\hline & (3) No opinion & $9(12.7)$ & $26(36.6)$ & & \\
\hline & (4) Agree & $29(40.9)$ & $55(77.5)$ & & \\
\hline & (5) Strongly agree & $16(22.5)$ & $71(100)$ & & \\
\hline 014. Patients with diabetes are predicted to have a & (1) Strongly disagree & $1(1.4)$ & $1(1.4)$ & 29.6 & 62.0 \\
\hline 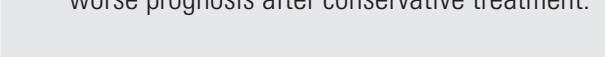 & (2) Disagree & $20(28.2)$ & $21(29.6)$ & & \\
\hline & (3) No opinion & $6(8.4)$ & $27(38)$ & & \\
\hline & (4) Agree & $37(52.1)$ & $64(90.1)$ & & \\
\hline & (5) Strongly agree & $7(9.9)$ & $71(100)$ & & \\
\hline 015. What percent of patients in your clinical & (1) $<5 \%$ & $32(45.1)$ & $32(45.1)$ & & \\
\hline treatment? & (2) $5 \%-10 \%$ & $23(32.4)$ & $55(77.5)$ & & \\
\hline & (3) $11 \%-20 \%$ & $7(9.9)$ & $62(87.4)$ & & \\
\hline & (4) $21 \%-30 \%$ & $6(8.4)$ & $68(95.8)$ & & \\
\hline & (5) $>30 \%$ & $3(4.2)$ & $71(100)$ & & \\
\hline
\end{tabular}

(orthopedic surgeons, rheumatologists, and physiatrists) treat this common condition, unpredictable clinical outcomes and prognosis continue to be reported. ${ }^{6,18)}$ In addition, as the number of patients with medical comorbidities such as diabetes increases, the incidence of surgical interventions for FS refractory to nonoperative treatment may also increase. ${ }^{7,9,19,20)}$ Kwaees and Charalambous ${ }^{20)}$ surveyed FS treatment preferences among surgeons and concluded that management of FS varies substantially among physicians and is based on personal experience and training rather than strong evidence.

Until now, there have been few comprehensive surveys that include the definition, classification, diagnosis, treatment, and prognosis of FS. The objective of this study is to identify a consensus of the definition, classification, diagnostic modality, preference for treatment, and prognosis of FS.

\section{METHODS}

This study was approved by Institutional Review Board of Keimyung University Dongsan Hospital (IRB No. 2018 06046).

\section{Survey Population}

A web-based survey questionnaire was designed by using the Google Docs survey tool (Google Inc., Mountain View, CA, USA). A link to access the survey was sent via e mail to 95 shoulder specialists able to answer questions related to FS. All 95 shoulder specialists were working at different residency or fellowship training hospitals in Korea. A questionnaire was considered completed only if all the questions were answered.

\section{Survey Details}

The total number of questions included in the survey was 18. Of those, 15 questions (three per each topic) were about definition, classification, diagnosis, treatment, and prognosis. Respondents were asked to indicate their level of agreement using the Likert scale: 1, strongly disagree; 2 , disagree; 3 , no opinion; 4, agree; and 5 , strongly agree. The remaining three questions were binary questions about the propriety of treatment for each stage of FS. Respondents were asked to answer whether each of the 12 suggested treatment choices is proper (1, proper; 2 , improper). The 12 treatments were education, supervised neglect, use of NSAIDs, oral corticosteroid medication, intra-articular 
Cho et al. A Consensus Survey of Shoulder Specialists on Frozen Shoulder

Clinics in Orthopedic Surgery • Vol. 12, No. 1, $2020 \bullet$ www.ecios.org

corticosteroid injection, subacromial corticosteroid injection, hydrodilation, MUA, arthroscopic capsular release, stretching exercise, muscle strengthening exercise, and thermoelectric therapy. We referred to the classification developed by Zuckerman and Rokito ${ }^{6}$ for definition and classification of FS in this survey.

\section{RESULTS}

Of the 95 shoulder specialists, 71 (74.7\%) completed the survey by answering all questions; 24 shoulder specialists did not reply within the specified deadline. All the questions and answers of this survey are presented in Table 1.

\section{Definition of FS}

On question $1,84.5 \%$ of the respondents either agreed or strongly agreed with the suggested definition of FS; $15.5 \%$ either disagreed or strongly disagreed. On question 2, $88.8 \%$ of the respondents either agreed or strongly agreed with the suggestion that FS should be categorized into the primary and secondary types; $8.4 \%$ either disagreed or strongly disagreed. Question 3 was about the suggested definition of limitation of motion in FS: 69\% either agreed or strongly agreed.

\section{Classification of FS}

Question 4 asked whether FS in patients with systemic disease (thyroid disease or hyperlipidemia) should be con- sidered secondary: $43.7 \%$ of the respondents either agreed or strongly agreed and $36.6 \%$ either disagreed or strongly disagreed. Question 5 asked whether FS in patients with diabetes should be considered secondary: $45.0 \%$ either agreed or strongly agreed and $40.9 \%$ either disagreed or strongly disagreed. Question 6 asked whether FS after overuse (repeated use in job or hobby) or minor trauma (strain, sprain, or contusion around the shoulder) should be regarded as primary: $67.6 \%$ either agreed or strongly agreed.

\section{Diagnosis of FS}

On questions 7 and 8, 71.9\% either agreed or strongly agreed with using plain radiographs for diagnosis and $64.8 \%$ either agreed or strongly agreed with using ultrasonography. However, on question 9 , only $36.5 \%$ either agreed or strongly agreed with using magnetic resonance imaging (MRI).

\section{Treatment of FS}

On question 10, $47.9 \%$ either agreed or strongly agreed that factors such as the type or dose of local anesthesia or the volume of normal saline, not the dose of corticosteroid, affect the outcome; $33.8 \%$ either disagreed or strongly disagreed. On question 11, 70.5\% either agreed or strongly agreed that an image-guided technique is necessary for intra-articular corticosteroid injection. On question 12 about the frequency of intra-articular corticosteroid injec-

\section{Table 2. Agreement on the Proper Treatment at Each Stage of Frozen Shoulder (016-018)}

\begin{tabular}{|lccc|}
\hline \multicolumn{1}{|c}{ Treatment } & Q16. Stage I (freezing) & Q17. Stage II (frozen) & Q18. Stage III (thawing) \\
\hline Education & $70(98.6)$ & $69(97.2)$ & $70(98.6)$ \\
\hline Supervised neglect & $53(74.7)$ & $52(73.2)$ & $60(84.5)$ \\
\hline Nonsteroidal anti-inflammatory drug & $69(97.2)$ & $67(94.4)$ & $61(85.9)$ \\
\hline Oral corticosteroid medication & $29(40.9)$ & $27(38)$ & $21(29.6)$ \\
\hline Intra-articular corticosteroid injection & $51(71.8)$ & $54(76.1)$ & $37(52.1)$ \\
\hline Subacromial corticosteroid injection & $45(63.4)$ & $40(56.3)$ & $32(45.1)$ \\
\hline Hydrodilation & $5(7)$ & $16(22.5)$ & $8(11.3)$ \\
\hline Manipulation under anesthesia & $4(5.6)$ & $36(50.7)$ & $19(26.8)$ \\
\hline Arthroscopic capsular release & $4(5.6)$ & $37(52.1)$ & $19(26.8)$ \\
\hline Stretching exercise & $63(88.7)$ & $69(97.2)$ & $68(95.8)$ \\
\hline Muscle strengthening exercise & $10(14.1)$ & $15(21.1)$ & $32(45.1)$ \\
\hline Thermoelectric therapy & $38(53.5)$ & $41(57.8)$ & $37(52.1)$ \\
\hline
\end{tabular}

Values are presented as number (\%). 
Cho et al. A Consensus Survey of Shoulder Specialists on Frozen Shoulder

Clinics in Orthopedic Surgery • Vol. 12, No. 1, $2020 \bullet$ www.ecios.org

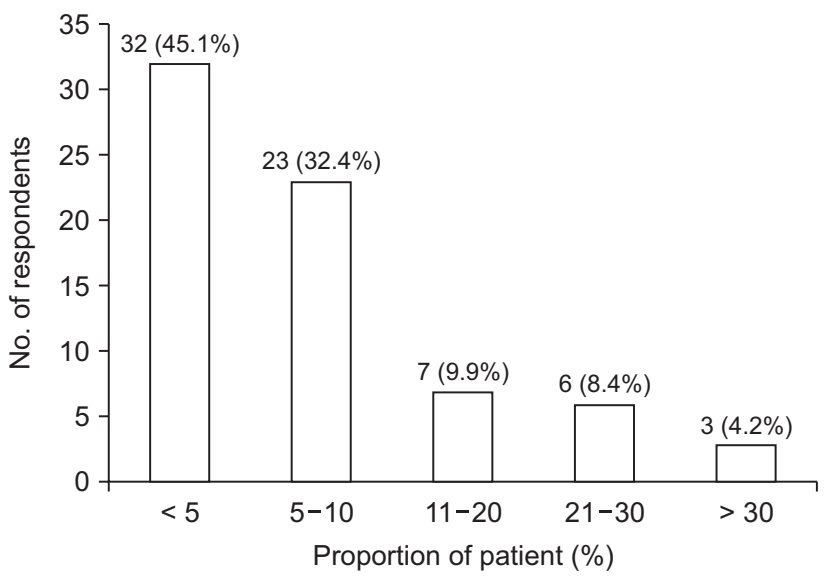

Fig. 1. Proportion of the patients who did not respond to conservative treatment.

tions in a single patient, 9.9\% responded not necessary; $62.0 \%$, once; $19.7 \%$, twice; $7.0 \%$, three times; and one respondent (1.4\%), four times or more.

Questions 16 through 18 were about the propriety of 12 specific treatments including nonoperative and operative strategies in each stage of FS (stage I, freezing; stage II, frozen; stage III, thawing). The responses are summarized in Table 2. In treatment of FS stage I, II, and III, the need for education was identified by $98.6 \%, 97.2 \%$, and $98.6 \%$ of the respondents, respectively; $97.2 \%, 94.4 \%$, and $85.9 \%$ agreed with using NSAIDs; $71.8 \%, 76.1 \%$, and $52.1 \%$ agreed with using intra-articular corticosteroid injection; and $88.7 \%, 97.2 \%$, and $95.8 \%$ agreed with using stretching exercise.

\section{Prognosis of FS}

On question $13,63.4 \%$ of the respondents either agreed or strongly agreed that intra-articular corticosteroid injection can reduce duration of FS. Question 14 asked whether patients with diabetes are predicted to have poor prognosis after conservative treatment: $62.0 \%$ either agreed or strongly agreed, whereas $29.6 \%$ either disagreed or strongly disagreed with this statement. Question 15 was about the percentage of patients who did not respond well to conservative treatment in clinical practice: $45.1 \%$ responded $<5 \%$; 32.4\%, 5\%-10\%; 9.9\%, $11 \%-20 \%$; $8.4 \%$, 21\%-30\%; and $4.2 \%,>30 \%$ (Fig. 1 ).

\section{DISCUSSION}

Our study revealed that there is a general consensus among Korean shoulder specialists on the definition and treatment of FS, but not on the classification of FS. Most respondents agreed with the propriety of education, supervised neglect, NSAIDs, intra-articular corticosteroid injection, and stretching exercise in treatment at each stage of FS. Among the respondents, $22.5 \%$ answered that more than $10 \%$ of their patients with FS did not respond to conservative treatment.

Recent reports have shown a general consensus on the definition of FS. ${ }^{6,12,13,17)}$ In a consensus study by Zuckerman and Rokito, $\left.{ }^{6}\right) 82 \%$ of the respondents either agreed or strongly agreed with the proposed definition of FS, and $85 \%$ either agreed or strongly agreed with the categorization of FS into the primary and secondary types. The results of our survey study are consistent with those of Zuckerman and Rokito. In our study, 84.5\% either agreed or strongly agreed with the suggested definition of FS (question 1), and $88.8 \%$ either agreed or strongly agreed that FS should be categorized into the primary and secondary types (question 2). Several studies suggested that FS diagnosed after trauma should be classified as secondary and can be attributed to the result of synovitis with fibrotic cascades. ${ }^{8,14,21)}$ However, in our study, $67.6 \%$ of respondents agreed with regarding FS after minor trauma or overuse as primary FS, possibly because of confusion in the definitions of trauma, minor trauma, and overuse, which may affect the assignment of disease category.

Unlike the definition of FS, the classification of FS appears to be controversial. Zuckerman and Rokito ${ }^{6}$ asked ASES members, "Is the division of secondary types of FS into intrinsic, extrinsic, and systemic appropriate?" and $66 \%$ either agreed or strongly agreed. Our study revealed the lack of consensus about questions 4 ("Do you think that FS diagnosed in patients with systemic disease such as thyroid disease or hyperlipidemia should be considered secondary FS?") and 5 ("Do you think that FS diagnosed in patients with diabetes should be considered secondary?"). On question 4, 43.7\% either agreed or strongly agreed and $36.6 \%$ either disagreed or strongly disagreed. This question had the highest no opinion responses (19.7\% of the respondents). On question 5, 45.0\% either agreed or strongly agreed and $40.9 \%$ either disagreed or strongly disagreed. Griesser et al. ${ }^{12)}$ systematically reviewed studies on primary FS in patients with diabetes and concluded that diabetes is a poor prognostic factor for FS. However, Zuckerman and Rokito ${ }^{6}$ suggested that FS in patients with systemic diseases such as diabetes or thyroid disease is secondary. Furthermore, there is a point of view that FS in patients with diabetes should be classified separately from primary or secondary FS. ${ }^{16)}$ Whether FS in patients with systemic disease should be considered as a subclass of secondary FS appears to be controversial. A new or modified 
classification of FS seems to be needed to achieve a consensus.

In patients with FS, radiographic studies including plain radiography, arthrography, ultrasonography, or MRI are used to exclude other causes of shoulder pain and can be complementary in the diagnosis. ${ }^{13)}$ In our study, most shoulder specialists agreed with using plain radiography (71.9\%) and ultrasonography (64.8\%) but fewer respondents agreed with using MRI (36.5\%) in the diagnosis of FS. These results demonstrate that shoulder specialists can diagnose FS through clinical presentation and minimum radiologic examination.

The treatment of FS remains controversial because the level of evidence for various treatments is limited. ${ }^{13)}$ Controlled prospective studies are difficult to design and perform because of controversies in the definition, classification, diagnosis, and stages of FS. Kwaees and Charalambous ${ }^{20)}$ reported a survey of FS treatment by 88 members of the British Elbow and Shoulder Society. The agreement was $67.8 \%$ for physiotherapy and $54 \%$ for corticosteroid injection used for treatment of stage II FS. The authors concluded that the management of FS varies substantially among physicians and is largely based on personal experience and training rather than strong evidence. Yet, we found a strong consensus on the proper treatment of FS: $97.2 \%$ agreed on education, $94.4 \%$ on NSAIDs, $76.1 \%$ on intra-articular steroid injection, and $97.2 \%$ on stretching exercise. Optimizing treatment depends on the recognition of the clinical stage at presentation because the condition progresses through predictable sequence. ${ }^{14)}$ Highquality clinical trials should be performed to compare the treatment options available to the clinicians.

Since Codman" stated in 1934 that "even the most severe cases recover with or without treatment in about 2 years" and "recovery is always sure and may be confidently expected," the perception that the natural history of FS is benign and self-resolving within 2 years has been overwhelming. ${ }^{1,11)}$ However, clinicians often see patients complaining of residual pain and loss of motion even at 2 years after the onset of the disease. ${ }^{8,9)}$ Several studies suggested that diabetes is a poor prognostic factor for clinical outcome after treatment. ${ }^{12,13,17)}$ In our study, $22.5 \%$ of the respondents answered that more than $10 \%$ of the patients with FS did not respond to conservative treatment. We asked whether patients with FS and diabetes are predicted to have poor prognosis after conservative treatment: $62.0 \%$ either agreed or strongly agreed. High-quality clinical trials would be necessary to evaluate the effectiveness of the treatment options and prognosis after treatment in patients with FS.

Our study has several limitations. First, the number of subjects is small. Nevertheless, the response rate was relatively high (74.7\%) and all respondents were shoulder specialists working at residency or fellowship training hospitals. Second, our interpretation of the survey results might be ambiguous because of no gold-standard cutoff percentage for the agreement. In conclusion, this survey study revealed a general consensus among shoulder specialists in the definition and treatment of FS. However, classification of FS was found to be controversial.

\section{CONFLICT OF INTEREST}

No potential conflict of interest relevant to this article was reported.

\section{ACKNOWLEDGEMENTS}

We thank 95 shoulder specialists who participated in this survey and Eun-Ji Jeon (Keimyung University Dongsan Hospital) for helping with data collection.

\section{REFERENCES}

1. Neviaser JS. Adhesive capsulitis of the shoulder: a study of the pathological findings in periarthritis of the shoulder. J Bone Joint Surg Am. 1945;27(2):211-22.

2. Bunker TD. Time for a new name for 'frozen shoulder'. Br Med J (Clin Res Ed). 1985;290(6477):1233-4.

3. Grey RG. The natural history of "idiopathic" frozen shoulder. J Bone Joint Surg Am. 1978;60(4):564.

4. Neviaser AS, Neviaser RJ. Adhesive capsulitis of the shoulder. J Am Acad Orthop Surg. 2011;19(9):536-42.
5. Wong CK, Levine WN, Deo K, et al. Natural history of frozen shoulder: fact or fiction? A systematic review. Physiotherapy. 2017;103(1):40-7.

6. Zuckerman JD, Rokito A. Frozen shoulder: a consensus definition. J Shoulder Elbow Surg. 2011;20(2):322-5.

7. Codman EA. The shoulder: rupture of the supraspinatus tendon and other lesions in or about the subacromial bursa. Boston, MA: Thomas Todd; 1934.

8. Hand C, Clipsham K, Rees JL, Carr AJ. Long-term outcome of frozen shoulder. J Shoulder Elbow Surg. 2008;17(2):231-6. 
9. Shaffer B, Tibone JE, Kerlan RK. Frozen shoulder: a longterm follow-up. J Bone Joint Surg Am. 1992;74(5):738-46.

10. Bell S, Coghlan J, Richardson M. Hydrodilatation in the management of shoulder capsulitis. Australas Radiol. 2003;47(3):247-51.

11. Eljabu W, Klinger HM, von Knoch M. Prognostic factors and therapeutic options for treatment of frozen shoulder: a systematic review. Arch Orthop Trauma Surg. 2016;136(1):1-7.

12. Griesser MJ, Harris JD, Campbell JE, Jones GL. Adhesive capsulitis of the shoulder: a systematic review of the effectiveness of intra-articular corticosteroid injections. J Bone Joint Surg Am. 2011;93(18):1727-33.

13. Hsu JE, Anakwenze OA, Warrender WJ, Abboud JA. Current review of adhesive capsulitis. J Shoulder Elbow Surg. 2011;20(3):502-14.

14. Neviaser AS, Hannafin JA. Adhesive capsulitis: a review of current treatment. Am J Sports Med. 2010;38(11):2346-56.

15. Oh JH, Oh CH, Choi JA, Kim SH, Kim JH, Yoon JP. Comparison of glenohumeral and subacromial steroid injection in primary frozen shoulder: a prospective, randomized short-term comparison study. J Shoulder Elbow Surg. 2011;20(7):1034-40.

16. Robinson CM, Seah KT, Chee YH, Hindle P, Murray IR. Frozen shoulder. J Bone Joint Surg Br. 2012;94(1):1-9.

17. Sheridan MA, Hannafin JA. Upper extremity: emphasis on frozen shoulder. Orthop Clin North Am. 2006;37(4):531-9.

18. Ryan V, Brown H, Minns Lowe CJ, Lewis JS. The pathophysiology associated with primary (idiopathic) frozen shoulder: A systematic review. BMC Musculoskelet Disord. 2016;17(1):340.

19. Kwaees TA, Charalambous CP. Rates of surgery for frozen shoulder: an experience in England. Muscles Ligaments Tendons J. 2016;5(4):276-9.

20. Kwaees TA, Charalambous CP. Surgical and non-surgical treatment of frozen shoulder: survey on surgeons treatment preferences. Muscles Ligaments Tendons J. 2015;4(4):420-4.

21. Levine WN, Kashyap CP, Bak SF, Ahmad CS, Blaine TA, Bigliani LU. Nonoperative management of idiopathic adhesive capsulitis. J Shoulder Elbow Surg. 2007;16(5):569-73. 